Research Article

\title{
Antibacterial, Antifungal, and Antidiabetic Effects of Leaf Extracts from Persea americana Mill. (Lauraceae)
}

\author{
Mercy Makopa (D), Benjamin Mangiza (D), Benjamin Banda (D), Winnie Mozirandi (D), \\ Molly Mombeshora $(\mathbb{D}$, and Stanley Mukanganyama
}

Department of Biochemistry, University of Zimbabwe, Mount Pleasant, Harare, Zimbabwe

Correspondence should be addressed to Stanley Mukanganyama; smukanganyama@medic.uz.ac.zw

Received 13 July 2020; Revised 29 October 2020; Accepted 30 October 2020; Published 11 November 2020

Academic Editor: Z. Beyir Huyut

Copyright (c) 2020 Mercy Makopa et al. This is an open access article distributed under the Creative Commons Attribution License, which permits unrestricted use, distribution, and reproduction in any medium, provided the original work is properly cited.

\begin{abstract}
Fruits and leaves of Persia americana are used in traditional medical practices. This study was carried out to determine the antibacterial, antifungal, and antidiabetic effects of the leaf extracts from P. americana. The antibacterial activities of the leaf extracts were evaluated against Klebsiella pneumoniae and Staphylococcus epidermidis while antifungal activities were determined against Candida albicans and Candida tropicalis. The antidiabetic potential of the extracts was determined against mammalian $\alpha$-glucosidase in vitro. The broth microdilution method was used to investigate the antibacterial and antifungal susceptibility of the microbial strains towards the leaf extracts. S. epidermidis was the most susceptible microbe out of the tested microorganisms. The acetone extract was the most potent extract against $S$. epidermidis with a minimum inhibitory concentration (MIC) of $50 \mu \mathrm{g} /$ $\mathrm{mL}$. At $100 \mu \mathrm{g} / \mathrm{mL}$, the ethanol:water extract $18 \%$ of $K$. pneumoniae cells remained viable. Cell viability after exposure to the dichloromethane (DCM) and methanol extracts was $28 \%$ against C. albicans and 8\% against C. tropicalis, respectively. The DCM: methanol and acetone extracts caused membrane damage in S. epidermidis exhibited by protein leakage. Only the acetone extract effected nucleic acid leakage. Screening of extracts' potential to inhibit the activity of $\alpha$-glucosidase was carried out spectrophotometrically following the production of p-nitrophenol from p-nitrophenol-glucopyranoside (substrate) at a wavelength of $405 \mathrm{~nm}$. Out of all the tested extracts, the methanolic extract showed the best inhibitory activity on $\alpha$-glucosidase enzyme in a time-dependent and dose-dependent manner. $\mathbf{K}_{i}$ and $\mathbf{K}_{\text {inact }}$ values were found to be $1.4 \mathrm{mg} / \mathrm{mL}$ and $2.4 \mathrm{U} / \mathrm{min}$, respectively, after incubation for 1 hour. It was concluded that the leaf extracts of $P$. americana contain phytochemicals with antibacterial, antifungal, and $\alpha$-glucosidase inhibitory effects. Further studies are required for the identification of the active compounds in the leaf extracts responsible for these observed effects.
\end{abstract}

\section{Introduction}

Plants are known to have naturally occurring chemicals that are bioactive meaning that they have the ability to interact with components of living tissue producing an effect [1]. The antimicrobial properties exerted by plants have been attributed to secondary metabolites [2]. Secondary metabolites or phytochemicals such as alkaloids, tannins, flavonoids, terpenoids, and glycosides have been studied [3]. Secondary metabolites have resulted in the development of systems that can efficiently isolate bioactive compounds in plants [4] with antimicrobial properties. Many drugs commonly used today are of herbal origin; about $25 \%$ of the prescription drugs dispensed in the USA contain at least one active ingredient derived from plant material [5].

Persea americana also known as the avocado plant is a tree that is indigenous to Central America. The avocado plant belongs to one of the oldest flowering plant families known as Lauraceae [6]. Different parts of the plant have received remarks for their therapeutic effects against skin infections, stomachaches, anaemia, skin ulcers, and diabetes [7]. Ajayi et al. [8] evaluated the effects of methanolic leaf extracts of P. americana against clinical strains of Escherichia coli and Pseudomonas aeruginosa. The study showed that the extracts possess potent antibacterial activities. The work by Ajayi et al. [8] attributed the antibacterial effects observed to 
the presence of secondary plant metabolites. Traditionally, $P$. americana is widely used as a source of medicine and food in many parts of the world. Leaves of the plant can be used to make tea and as flavorings in beef as well as bean dishes [5]. In developing countries, problems are associated with the means of managing diabetes using antidiabetic drugs due to availability and affordability. Drug candidates have been developed from the phytochemical constituents isolated from medicinal plants. A variety of plants are being studied for their antidiabetic potential [9].

Candida albicans is an etiological microbe for fungal infections. In a healthy individual, the growth of C. albicans is regulated by bacteria and other microorganisms that are part of the natural flora. The uncontrolled growth of C. albicans results in candidiasis [10]. Reports have documented a shift from $C$. albicans as the cause of the majority of invasive infections toward non-C. albicans species. C. tropicalis is classified as one of the most potent yeasts of the non-albicans Candida group [11]. Previous studies have shown that the Candida species are susceptible to plant extracts. Extracts from the Combretum molle, Piper capense, Solanum aculeastrum, Syzygium cordatum, and Zanthoxylum davyi showed antifungal properties against C. albicans [12].

Antibacterial properties of medicinal plants are being increasingly reported from different parts of the world. Staphylococcus epidermidis is a Gram-positive bacterium that is spherically shaped and a facultative anaerobe [13]. It is part of the normal human flora, typically skin flora, and less associated with the mucosal flora in humans [14]. The bacterium has been shown to be less pathogenic in humans, but virulence of the strain has been reported in immunocompromised individuals, particularly in nosocomial infections [15]. K. pneumoniae is a Gram-negative, rodshaped, non-encapsulated, facultative anaerobic and lactose fermenting bacterium. The bacterium is responsible for causing nosocomial infections and has been reported to be resistant to beta lactam antibiotics such as penicillin [16].

The enzyme $\alpha$-glucosidase is involved in the breakdown of carbohydrates during digestion. The enzyme catalyses reactions that result in the release of the terminal alphaglucose residue from disaccharides and oligosaccharides [17]. Avocado leaves contain phytochemicals such as flavonoids and phenols in the fruit or the seed and these have been reported to have antidiabetic effects [18]. A therapeutic approach to treat diabetes is to decrease postprandial hyperglycaemia. Avocado leaves have been used locally to make avocado tea used as a means of managing diabetes [19]. It is, therefore, important to investigate the effects of the leaf extracts on $\alpha$-glucosidase so as to validate its use as a means of managing diabetes. The aim of the study was to evaluate the antimicrobial and antidiabetic activity of leaf extracts from $P$. americana.

\section{Materials and Methods}

2.1. Chemicals and Reagents. All the chemicals used were obtained from Sigma Aldrich (Darmstadt, Germany). All solvents used were of analytical reagent grade; these were acetone, methanol, n-hexane, ethanol, ethyl acetate, dichloromethane (DCM), and chloroform. Dimethyl sulfoxide (DMSO) was used for dissolving the crude extract as well as other reagents used: Sabouraud dextrose broth (SDB), Sabouraud glucose $2 \%$ agar (SGA), Luria Bertani broth, 3-(4,5-dimethylthiazolyl)-2,5-diphenyltetrazolium bromide (MTT), and potassium hydroxide $(\mathrm{KOH})$. The drugs miconazole and fluconazole were obtained from Sigma-Aldrich (Germany). C. albicans (NCPF 3255) was purchased from Sigma Aldrich. A clinical strain of C. tropicalis was obtained from the Department of Medical Microbiology at Parirenyatwa Hospital in Harare, Zimbabwe.

2.2. Plant Collection and Preparation. P. americana leaves were collected from a tree in Chitungwiza, Seke, at house number 9209 Unit K, $177^{\circ}$ Southwest of Chitungwiza Baptist (Greater Harare, Zimbabwe). Leaves were taken to the National Herbarium and Botanical Gardens of Zimbabwe for identification. The leaves were washed with tap water to remove dirt and dried in an incubator at $40^{\circ} \mathrm{C}$ for $72 \mathrm{hrs}$. Dried leaves were then ground using traditional pestle and mortar to fine powder, weighed, and put in a plastic beaker.

\subsection{Extraction of Phytochemicals Using Differential Solvents}

2.3.1. Extraction with DCM: Methanol and Hydroethanolic Water Solvent (Total Extraction). Two sets of solvent mixtures were used: (1) DCM:methanol in the ratio $1: 1$ and (2) ethanol:water in the ratio $1: 1$. The extracts were prepared by adding $20 \mathrm{~g}$ of the ground powder to $100 \mathrm{~mL}$ of the solvents. The mixture of the solvent and the leaf powder was filtered to obtain the extract. During the filtration process, cotton was used first so as to trap the undissolved matter. The filtrate obtained was further filtered using a filter paper Whatman no. 1 so as to trap the particles that were able to pass through the cotton. The filtrate was collected and dried under a fan.

2.3.2. Serial Exhaustive Extraction. Serial exhaustive extraction of phytochemicals of the leaf powder from $P$. americana was carried out serially using solvents of increasing polarity: hexane, dichloromethane, ethyl acetate, acetone, ethanol, methanol, and water. A total mass of $30 \mathrm{~g}$ of leaf powder was used in the first serial solvent (hexane) and left for 24 hours for extraction. After 24 hours, the contents in the beaker were filtered. The retained leaf residue was dried and extracted with another solvent. This was repeated until all the solvents had been used for extraction. Ultimately, a total of 7 extracts were obtained.

\subsection{Screening for Antifungal and Antibacterial Activity of Leaf Extracts from $P$. americana}

2.4.1. Growth of Microorganisms. Overnight cultures were prepared by picking 3 colonies from an agar plate of the microbe and inoculating into the relevant broth followed by 
incubating at $37^{\circ} \mathrm{C}$ for $24 \mathrm{hrs}$ in a Lab Companion incubator (Jeio Tech, Seoul, Korea). C. tropicalis and C. albicans were grown in SDB while Luria broth was used for the growth of K. pneumoniae and S. epidermidis. Cells were standardised using $0.5 \mathrm{McF}$ arland standard to give a working concentration of $2 \times 10^{6} \mathrm{cfu} / \mathrm{mL}$.

2.4.2. Screening for Antifungal and Antibacterial Activity. Screening for antifungal and antibacterial activity of extracts was determined using the broth microdilution method [20]. Extracts from serial exhaustive extraction and total extraction were tested against C. albicans, C. tropicalis, S. epidermidis, and K. pneumoniae. Extracts were dissolved in DMSO and concentrations of 25,50 , and $100 \mu \mathrm{g} / \mathrm{mL}$ were prepared by diluting using media. A volume of $100 \mu \mathrm{L}$ of extract was added to the wells of a 96-well microplate. To the test wells, $100 \mu \mathrm{L}$ of bacterial cells with a concentration of $2 \times 10^{6} \mathrm{cfu} / \mathrm{mL}$ was added. The wells with media only (SDB/ LB) were included to check for sterility. Wells with cells only served as the negative control. Miconazole and levofloxacin were used as the reference drugs for fungi and bacteria, respectively. Pre-incubation readings of the absorbance were measured at $590 \mathrm{~nm}$ using a Tecan microplate reader (Tecan Genios-Pro microplate reader, Grödig, Austria). The plate was incubated for $24 \mathrm{hrs}$ without shaking at $37^{\circ} \mathrm{C}$ in a Lab Companion incubator. A post-incubation reading of the cell density was determined. A colorimetric determination for metabolically active cells after exposure to the extract was performed by adding of $25 \mu \mathrm{L}$ aliquots of $1 \mathrm{mg} / \mathrm{mL} \mathrm{3-(4,5-}$ dimethylthiazol-2-yl)-2,5-diphenyltetrazolium bromide (MTT) to each of the wells of the 96-well plate and incubating the plate at $37^{\circ} \mathrm{C}$ for $2 \mathrm{hrs}$. In the presence of metabolically active fungi or bacteria, the yellow MTT dye is reduced to a purple formazan [21]. Colour intensity was determined by reading absorbance values at $590 \mathrm{~nm}$ using a Tecan microplate reader, where there was partial inhibition and MIC could not be determined. Data are presented as percentage cell viability. Percentage cell viability was obtained using the following:

$$
\text { cell viability }(\%)=\frac{\text { mean OD sample }}{\text { mean OD positive control }} \times 100 \text {. }
$$

2.5. Determination of the Effects of P. americana Extracts on Nucleic Acid Leakage. Propidium iodide is a dye that is capable of binding to nucleic acids. The dye is unable to enter viable cells, making it useful for determining the effects of plant extracts on bacterial membranes. To determine the effect of extracts from $P$. americana on the integrity of bacterial and fungal membranes, the method outlined by ElNakeeb et al. [22] with minor modification was used. An overnight culture of $S$. epidermidis cells was used in the assay. The optical density $\left(\mathrm{OD}_{600}\right)$ of cells was adjusted to 1.5 by diluting with $0.9 \%$ saline solution. The negative control contained $3 \mathrm{~mL}$ of cells and $3 \mathrm{~mL}$ media. The positive control contained $3 \mathrm{~mL}$ of cells and $3 \mathrm{~mL}$ of $0.1 \%$ sodium dodecyl sulphate. The cells were exposed to three concentrations of the most potent extract. The exposed cells were incubated at $37^{\circ} \mathrm{C}$ for 30 mins. After incubation, $1 \mathrm{~mL}$ of the cells was centrifuged for 1 minute at $11000 \mathrm{rpm}$ using a Geratebau microcentrifuge (Engelsdorf, Germany). The pellet was washed with $1 \mathrm{~mL}$ saline and $3 \mu \mathrm{L}$ of propidium iodide was added to the mixture. The mixture was left to stand in the dark for 10 minutes. Fluorescence was measured at excitation and emission wavelengths of $544 \mathrm{~nm}$ and $612 \mathrm{~nm}$, respectively, using a $f_{\max }$ microplate spectrofluorometer (Molecular Devices, Sunnyvale, USA).

2.6. Determination of the Effects of Extracts from P. americana on Protein Leakage. Determination of protein leakage was carried out according to the method by $\mathrm{Du}$ et al. [23] with modifications. An overnight culture of S. epidermidis cells was suspended in $0.9 \%$ saline solution to give $\mathrm{OD}_{600}=1.5$. The cell suspension was exposed to plant extracts at concentrations of half the MIC ( $1 / 2 \mathrm{MIC})$, MIC, and double the MIC $\left(2 \times\right.$ MIC). The samples were incubated at $37^{\circ} \mathrm{C}$ with shaking (100 rpm) for $2 \mathrm{hrs}$. Cell suspension aliquots of $500 \mu \mathrm{L}$ were centrifuged at $4000 \mathrm{rpm}$ for 4 minutes. To $50 \mu \mathrm{L}$ of the supernatant, $950 \mu \mathrm{L}$ of Bradford reagent was added to determine the protein content using Bradford's method [24]. The controls used were $3 \%$ DMSO, $0.1 \%$ SDS, and untreated cells. Bovine serum albumin (BSA) was used as a standard protein in the Bradford assay. The colour was allowed to develop for $10 \mathrm{~min}$ before the absorbance was measured at $590 \mathrm{~nm}$ using a Tecan GeniosPro microplate reader.

\subsection{Effects of Extracts from P. americana on $\alpha$-Glucosidase from Male Sprague-Dawley Rats}

2.7.1. Preparation of $\alpha$-Glucosidase from male Sprague-Dawley rats. The study was approved by Departmental of Board of Biochemistry (Paper HBC 470 7092018). Five male Sprague-Dawley rats weighing 90-160 g purchased from the Animal House at the University of Zimbabwe were used as a source of $\alpha$-glucosidase. Animals were maintained and handled according to the recommendations of the good laboratory practice and animal handling (NIH) guidance for the care and use of laboratory animals, Publication No. 85-23, 1985. The rats were fed with certified food pellets rodent combroids (National foods (PVT), Ltd., Harare, Zimbabwe) ad libitum and allowed free access to drinking water. After $22 \mathrm{hrs}$ of fasting, the rats were sacrificed by cervical dislocation. The abdominal cavity was opened by means of dissection. Parts of the small intestine just below the duodenum and above the ceacum were collected from the animals. The collected intestines were cleaned thoroughly using $0.9 \%$ saline. Small pieces of the intestines were minced on ice. The liver and kidney samples were cut into suitable pieces and homogenized in $10 \mathrm{mM}$ PBS $\mathrm{pH} 7.4$ containing $1 \%$ Triton X-100 with a motor driven PotterElvehjem homogenizer type R2R (Heidolph Elektro KG., Kelheim, Germany). The homogenate was centrifuged at $12000 \mathrm{rpm}$ for $15 \mathrm{mins}$. Butanol was added in the ratio $1: 1$ to the supernatant fraction. The tubes were capped and a postmitochondria supernatant fraction was prepared by 
centrifugation at $7500 \mathrm{rpm}$ for $30 \mathrm{~min}$ at $2-4^{\circ} \mathrm{C}$ in a Beckman Optima LE-80 k ultracentrifuge (Beckman Instruments Inc., California, USA). The resultant mixture was centrifuged at $20000 \mathrm{rpm}$ for $30 \mathrm{mins}$. The aqueous layer was collected and stored as the crude enzyme. The crude enzyme was separated into $1 \mathrm{~mL}$ aliquots and frozen at $-80^{\circ} \mathrm{C}$. All enzyme preparations were carried out at $4^{\circ} \mathrm{C}$. Protein content in the cytosolic fractions was determined using the Lowry method [25].

2.7.2. Determining the Effects of Extracts from P. americana on $\alpha$-Glucosidase Activity. The assay was carried out by slightly modifying the method used by Bräunlich et al. [26]. The $\alpha$-glucosidase was dissolved in $100 \mathrm{mM}$ phosphate buffer $\mathrm{pH} 6.8$ and used as the enzyme extract. p-Nitrophenyl- $\alpha$-D-glucopyranoside (pNPG) was used as the substrate. Leaf extracts were used in the concentration ranging within $0-100 \mu \mathrm{g} / \mathrm{mL}$. No plant extract was added to the samples treated as controls. Equal volumes $(50 \mu \mathrm{L})$ of PBS pH 7.4, enzyme, and extract were pre-incubated for 10 mins at $37^{\circ} \mathrm{C}$. Further $1 \mathrm{hr}$ incubation was allowed after adding $50 \mu \mathrm{L}$ of the substrate $5 \mathrm{mM}$ pNPG. Acarbose was used as the reference inhibitor. Absorbance was read at $405 \mathrm{~nm}$ using a Stat fax 2100 micro-plate reader (Awareness Technologies Inc, Westport, USA).

2.7.3. Determination of Time-Dependent Effects of Extracts from $P$. americana on $\alpha$-Glucosidase. Inactivation of $\alpha$-glucosidase was determined using modified methods of Kim et al. [27] as well as by Chelladurai and Chinnachamy [28]. The enzyme and extract were incubated at $37^{\circ} \mathrm{C}$. Aliquots were withdrawn at $60 \mathrm{~min}$ intervals for $5 \mathrm{hrs}$ and $\alpha$-glucosidase activity was determined as described before. The inactivation parameters $\mathbf{K}_{\text {inact }}$ and $\mathbf{K}_{i}$ were obtained by plotting graphs of the percentage of remaining enzyme activity over time. To investigate concentration-dependent inactivation, incubations were set up for time-dependent inactivation with varying concentrations of leaf extracts at $50,500,1000,1500$, and $2000 \mu \mathrm{g} / \mathrm{mL}$.

2.8. Statistical Analysis. Data analyses were performed using GraphPad Prism 5 for Windows version 5.03 Software (GraphPad Prism Inc., San Diego, CA, USA). Levels of significance were determined using one-way ANOVA with the Dunnet multiple comparison posttest. All data were expressed as mean \pm standard deviation, and $p \leq 0.05$ values were considered as statistically significant.

\section{Results}

3.1. Effects of Extracts from P. americana on the Growth of K. pneumoniae, S. epidermidis, C. albicans, and C. tropicalis. The extracts from $P$. americana were tested for their antimicrobial activities against 2 bacterial strains and 2 fungal strains. The results are reported in Table 1 . The ethanol:water extract resulted in cell viability of less than $50 \%$ against all 4 test strains. Maximal activity of the ethanol:water extract was observed for S. epidermidis with total inhibition at $100 \mu \mathrm{g} /$ $\mathrm{mL}$ of the extract. Out of the tested extracts, K. pneumoniae and $S$. epidermidis were most susceptible to the acetone extract while C. albicans and C. tropicalis were most susceptible to the DCM and methanol extracts, respectively. As results of MIC determinations, the extracts from $P$. americana leaf inhibited the growth of S. epidermidis, with the MICs from 50 to $100 \mu \mathrm{g} / \mathrm{mL}$ (Table 1). The best activity of all extracts against all the test strains was obtained with the acetone extract against $S$. epidermidis showing the lowest MIC value of $50 \mu \mathrm{g} / \mathrm{mL}$. It was noted that the Gram-positive S. epidermidis showed greater susceptibility (total inhibition, $30 \%$ cell viability) towards the extracts from $P$. americana compared to the Gram-negative K. pneumoniae (18-77\% cell viability).

For the fungal strains, $C$. tropicalis showed greater susceptibility towards the extracts from $P$. americana with a minimum cell viability of $8 \%$ when exposed to the methanol extract compared to $C$. albicans with a minimum cell viability of $28 \%$ when exposed to the DCM extract. MIC for reference drug was $6.25 \mu \mathrm{g} / \mathrm{mL}$ levofloxacin against $K$. pneumoniae, $1.56 \mu \mathrm{g} / \mathrm{mL}$ levofloxacin against S. epidermidis, $12.5 \mu \mathrm{g} / \mathrm{mL}$ miconazole against C. albicans, and $6.25 \mu \mathrm{g} / \mathrm{mL}$ miconazole against C. tropicalis. Based on the results that the ethanol:water, DCM:methanol, and acetone extracts from $P$. americana were the most potent in inhibiting the growth of $S$. epidermidis, the effects of the three extracts on the integrity of the membrane of the bacterial were determined.

3.2. Effect of P. Americana Leaf Extracts on Membrane Integrity of S. epidermidis. The ability and the extent of the ethanol:water, DCM:methanol, and acetone to disrupt the membrane of $S$. epidermidis as a mode of action were assessed by investigating the effects of extracts on the leakage of proteins and nucleic acids. Protein content was estimated after S. epidermidis was separately exposed to the 3 extracts and the results are shown in Figure 1.

All the 3 extracts showed significant protein leakage at $2 \times$ MIC. At concentrations of $1 / 2 \mathrm{MIC}$ and MIC, protein leakage was not significantly different from that of untreated cells.

For the nucleic acid results (Figure 2), membrane disruption was evidenced by an increased uptake of propidium iodide by $S$. epidermidis cells exposed to $2 \times$ MIC of the acetone extract in comparison to the unexposed cells $(p<0.05)$ (Figure 2(c)). At concentrations of $1 / 2 \mathrm{MIC}$ and MIC, the acetone extract and the rest of the extracts were not able to cause significant nucleic acid leakage from S. epidermidis cells when compared to the control.

3.3. Effects of Extracts from P. americana on $\alpha$-Glucosidase Activity. The effects of extracts obtained by serial exhaustive extraction from $P$. americana on the activity of $\alpha$-glucosidase enzyme are shown in Figure 3. The standard inhibitor acarbose was observed to inhibit the activity of crude enzyme. Increase in concentration of inhibitor resulted in a 
TABle 1: Effects of extracts from P. americana on the cell viability of K. pneumoniae, S. epidermidis, C. albicans, and C. tropicalis.

\begin{tabular}{|c|c|c|c|c|}
\hline \multirow{2}{*}{ Extract } & \multicolumn{4}{|c|}{ Cell viability (\%) } \\
\hline & K. pneumoniae & S. epidermidis & C. albicans & C. tropicalis \\
\hline Ethanol:water & 18 & $\mathrm{MIC} 100 \mu \mathrm{g} / \mathrm{mL}$ & 39 & 14 \\
\hline DCM:methanol & 34 & MIC $100 \mu \mathrm{g} / \mathrm{mL}$ & 67 & 92 \\
\hline Hexane & - & - & 73 & 84 \\
\hline DCM & - & - & 28 & 52 \\
\hline Ethyl acetate & 26 & 30 & 77 & - \\
\hline Acetone & 25 & MIC $50 \mu \mathrm{g} / \mathrm{mL}$ & 70 & 76 \\
\hline Ethanol & - & - & 59 & 32 \\
\hline Methanol & - & - & 55 & 8 \\
\hline Water & 77 & - & 63 & 91 \\
\hline
\end{tabular}

(-): cell viability not determined; in bold: cell viability of less than $50 \%$.

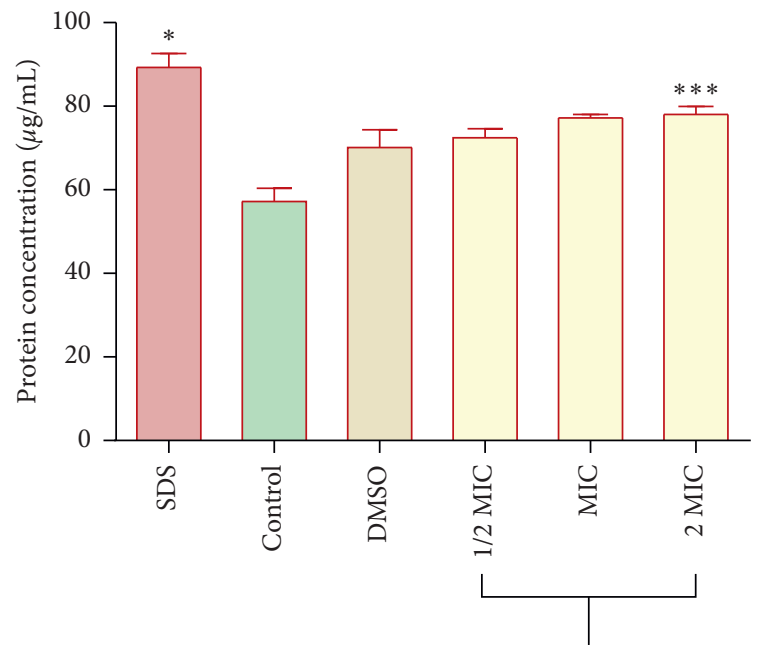

Concentration of ethanol: water extract $(\mu \mathrm{g} / \mathrm{mL})$

(a)

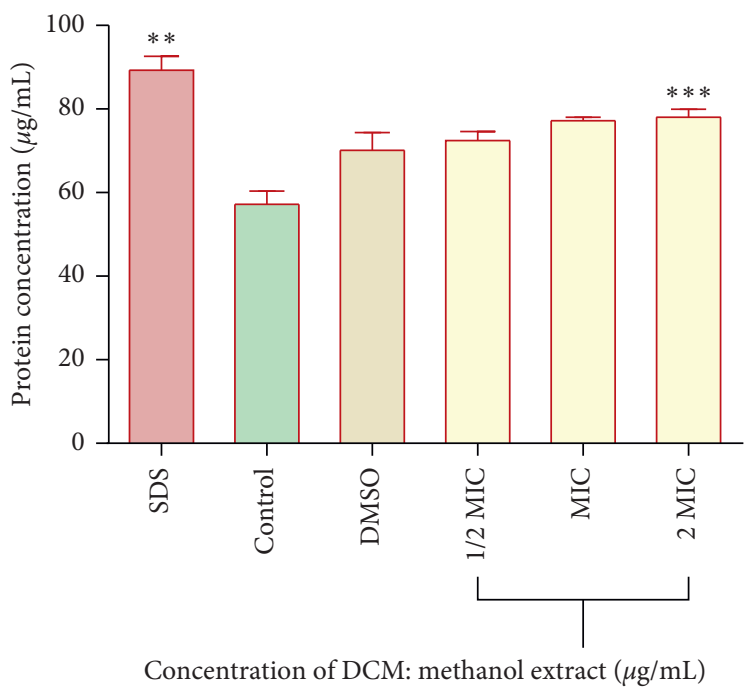

(b)

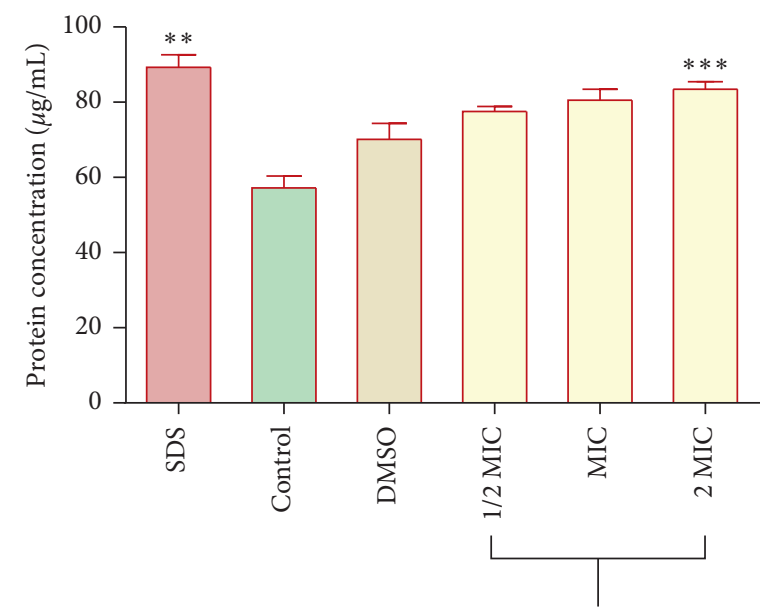

Concentration of acetone extract $(\mu \mathrm{g} / \mathrm{mL})$

(c)

Figure 1: Effect of leaf extracts from $P$. americana on protein leakage from S. epidermidis cells at 1/2 MIC, MIC, and 2 MIC. (a) Water: ethanol extract, (b) DCM:water extract, and (c) acetone extract. The values shown are for mean \pm standard deviation for $n=3$. Untreated cells were the negative control and SDS (sodium dodecyl sulphate) was the positive control. The asterisks indicate a significant difference from the control with ${ }^{* *} p<0.01$ and ${ }^{* * *} p<0.001$. 


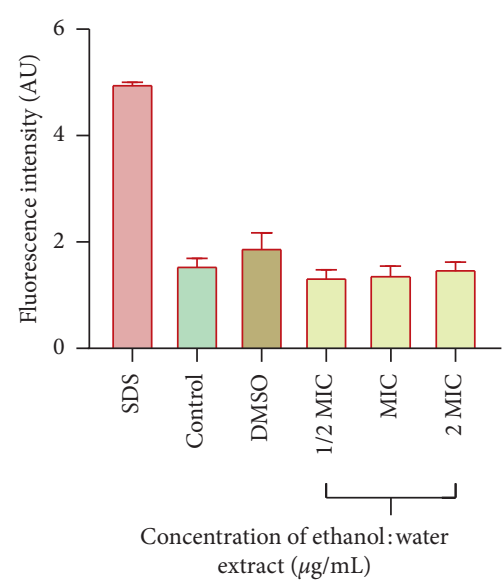

(a)

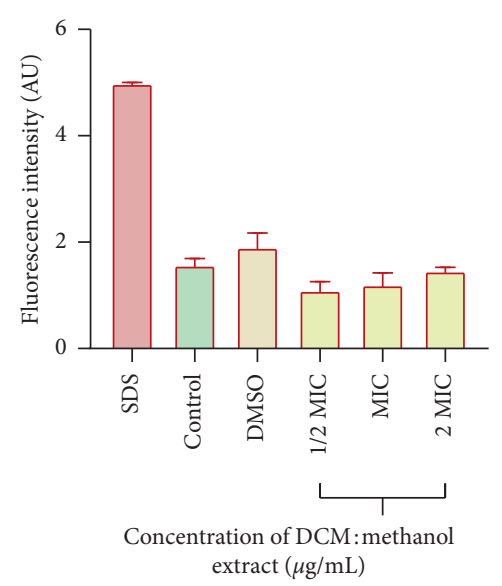

(b)

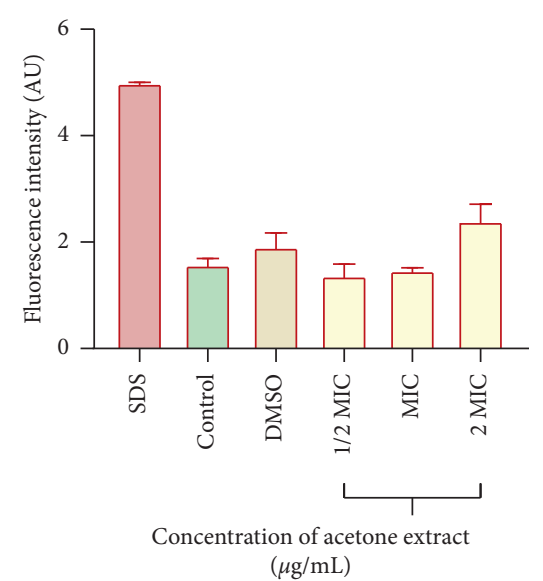

(c)

FIgURe 2: Effect of leaf extracts from P. americana on nucleic acid leakage from (S) epidermidis cells at 1/2 MIC, MIC, and 2 MIC. (a) Ethanol:water extract, (b) DCM:methanol extract, and (c) acetone extract. The values shown are for mean \pm standard deviation for $n=3$. Untreated cells were the negative control and SDS (sodium dodecyl sulphate) was the positive control. The asterisks indicate a significant difference from the control with ${ }^{*} p<0.05$ and ${ }^{* * *} p<0.001$.

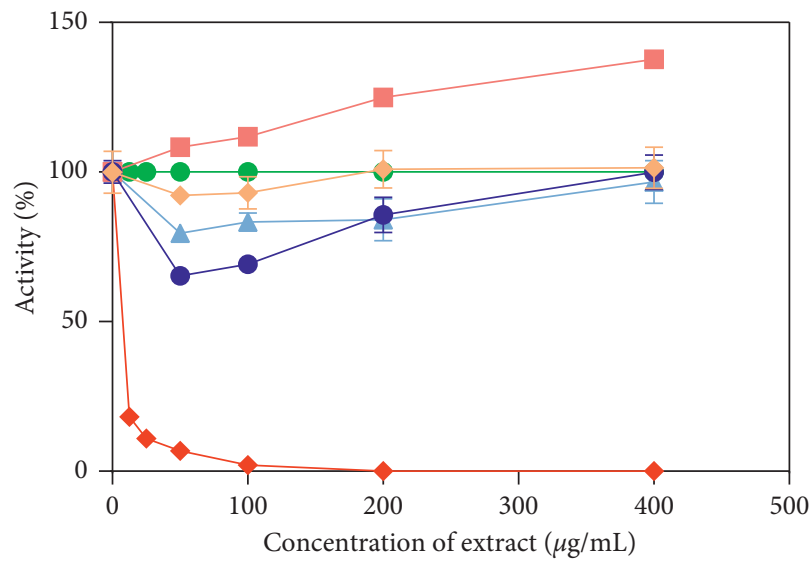

Extract key

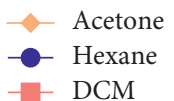

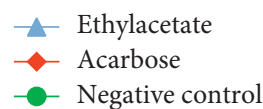

(a)
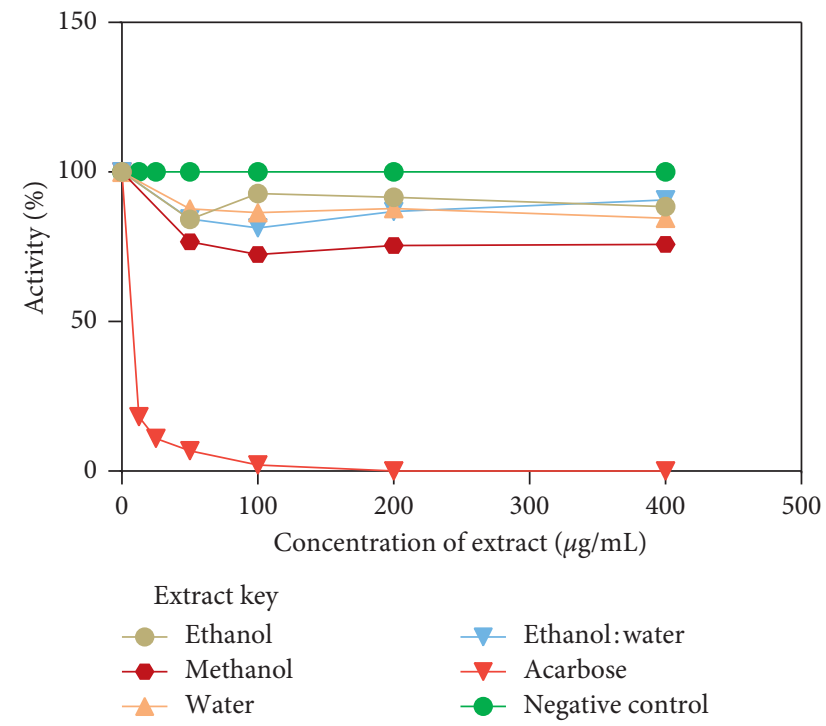

(b)

FIgURE 3: The effects of extracts of intermediate polarity and non-polar extracts (a) and polar extracts (b) from P. americana on the activity on $\alpha$-glucosidase.

decrease in the activity of the enzyme. Complete inhibition was achieved at a concentration above $100 \mu \mathrm{g} / \mathrm{mL}$ of acarbose. With respect to extracts prepared using non-polar solvents, a slight decrease in the activity of $\alpha$-glucosidase activity was observed with an increase in the concentration of the extract up to $100 \mu \mathrm{g} / \mathrm{mL}$. Activity of the enzyme was uninhibited by the DCM extract (Figure 3(a)). A decrease in activity of the enzyme with respect to hexane extract was observed at extract concentration between 0 and $50 \mu \mathrm{g} / \mathrm{mL}$. At concentrations above $50 \mu \mathrm{g} / \mathrm{mL}$, enzyme activity was observed to increase with increase in concentration of hexane extract. The change in activity of the enzyme in the presence of the non-polar solvent extracts was not significant. Extracts of intermediate polarity, ethyl-acetate, and acetone had a slight inhibitory potential towards the enzyme but however the change in activity was not significant (Figure 3(a)). The polar solvents presented with a decrease in activity of the enzyme with increase in polarity of the solvent of extraction. The methanolic extract was the most potent inhibitor, inhibiting about $25 \%$ of the enzyme (Figure 3(b)). However, all extracts did not cause a significant change in the activity of $\alpha$-glucosidase. The initial screening using all extracts was to determine the extract with the most potent inhibitory activity. The extract with the most potent inhibitory activity, the methanol extract, was used in subsequent assays. 
3.4. Inactivation of $\alpha$-Glucosidase by the Methanol Extract of $P$. americana. As the most potent extract that inhibited the activity of alpha-glucosidase shown in Figure 3(b), the timedependence effects on $\alpha$-glucosidase activity of the methanol extract were determined. The methanol extract inactivated $\alpha$-glucosidase in a time-dependent manner (Figure 4(a)).

The concentration-dependent inactivation of the activity of $\alpha$-glucosidase by the methanol extract was determined. A general decrease in activity was observed with increase in time at all concentrations of extract (Figure 4(b)).

The inactivation parameters $\mathbf{K}_{\text {inact }}$ and inhibition constant $\mathbf{K}_{i}$ of the methanol extract with $\alpha$-glucosidase were obtained by analysing the data using the following:

$$
\frac{\left[\operatorname{In}\left(E / E_{0}\right)\right]}{t}=-\left(\mathrm{K}_{\text {inact }} \cdot \frac{[l]}{[l]}+\mathrm{K}_{i}\right) \text {. }
$$

Data from the concentration-dependent effects was replotted (Figure 5) to obtain values for $\mathbf{K}_{\text {inact }}$ and $\mathbf{K}_{i}$ and these were found to be $1.4 \mathrm{mg} / \mathrm{mL}$ and $2.4 \mathrm{U} / \mathrm{min}$, respectively.

\section{Discussion}

The study aimed to determine the antimicrobial activities of leaf extracts from $P$. americana against $K$. pneumoniae, S. epidermidis, C. albicans, and C. tropicalis as well as the antidiabetic effects of the extracts. Studies have shown that plants are a source of drug development [29]. Plants contain various active compounds that can be used to develop synthetic products used in the food, cosmetics, and pharmaceutical industries. Previous studies have shown that $P$. americana possesses a variety of phytochemicals that are beneficial to mankind [5].

The ethanol:water extract was the most potent against all 4 test strains. High potency of the hydroethanolic extracts has been reported elsewhere against Candida [30] and bacteria [31]. Maximal activity of the ethanol:water extract was observed against $S$. epidermidis with total inhibition at $100 \mu \mathrm{g} / \mathrm{mL}$ of the extract. The hydroethanolic media of extraction are known to solubilise alkaloids often possessing compounds that have significant physiological and therapeutic effects [32]. K. pneumoniae and S. epidermidis were most susceptible to the acetone extract. Acetone extracts have shown noteworthy reduction in the growth of various microbes [33, 34]. In other studies [8], the acetone extract was shown to particularly extract tannins, flavonoids, terpenoids, alkaloids, and saponins from $P$. americana leaves, which may be attributed to the antibacterial activity observed in this study. The antimicrobial activity of extracts from $P$. americana was evaluated against both Gram-positive (S. epidermidis) and Gram-negative (K. pneumoniae) bacteria. S. epidermidis showed greater susceptibility towards the majority of the extracts from $P$. americana compared to K. pneumoniae (Table 1). As Gram-negative bacteria, K. pneumoniae tend to be less susceptible to antimicrobial agents than Gram-positive S. epidermidis, because of the presence of the extra protection given by the outer membrane [35]. The water extract showed limited reduction in the viability of all tested strains (63-91\%). Similar results were obtained, in the study by Korukluoglu et al. [36]. In their study, they showed that the aqueous extract of olive leaves had reduced antibacterial effect against several Grampositive and Gram-negative bacteria. Nevertheless, some studies support that aqueous extracts possess antimicrobial activity against pathogenic bacteria [37, 38]. For the fungal strains, C. tropicalis extract showed susceptibility towards the extracts from $P$. americana as indicated by reduced cell viability especially towards the water:ethanol (14\%), ethanol (32\%), and methanol (8\%) extracts. Susceptibility of C. tropicalis has been reported in other studies [39, 40]. Susceptibility of microbes to extracts: K. pneumoniae (4/ 5-80\%), S. epidermidis (4/4-100\%), C. albicans (2/9-22\%), and C. tropicalis (3/9-33\%), generally showing that bacteria were more susceptible to extracts compared to fungi. In a study on the antimicrobial activity of herbal extracts by Khan et al. [40], similar results were obtained where Terminalia arjuna and Eucalyptus globulus showed greater activity towards bacteria in comparison to fungi. When compared to fungi, bacteria, whether Gram-positive or Gram-negative, usually respond differently to antimicrobials. The underlying reasons for these varied responses are not yet fully understood at present, but the chemical composition of outer cellular layers is the most probable factor of prime importance [41]. The fact that the cell wall of bacteria is made up of peptidoglycan [35] while that of fungi is made up of chitin [42] may be one of the explanations, if the antimicrobial targets cell wall synthesis. However, it should be noted that with other antimicrobials some degree of "cross-activity" occurs pertaining to bacteria and fungi. Such differences in susceptibility to extracts bring the question of the mode of action of the extracts showing bioactivity.

The mechanism of action of the 3 most potent extracts from $P$. americana (Table 1 ) was determined. The three most potent extracts against $S$. epidermidis were the ethanol:water, DCM:methanol, and the acetone extracts. Antibacterial agents generally act on the membranes of microbes to affect disruption and permeabilization [43]. The ability and the extent of plant extracts to permeabilise $S$. epidermidis membrane were assessed by the protein (Figure 1) and nucleic acid (Figure 2) assays. Exposure of cells to all 3 extracts at a concentration of $2 \times$ MIC caused an increase in protein leakage indicating membrane permeabilization. Viable bacterial cells are impermeable to propidium iodide, a fluorescent dye; but upon membrane disruption or permeabilization, the dye can enter the cells. Significant fluorescence was observed in bacterial cells treated with the acetone extract at a concentration of $2 \times$ MIC (Figure 2(c)), suggesting inner membrane permeabilization. These results are somewhat in agreement with previous studies conducted on water/ethanol extracts of Cissus welwitschii against $\mathrm{Ba}$ cillus cereus by Moyo and Mukanganyama [44]. In the study, the authors observed protein and nucleic acid leakage effects of the extracts. Other studies have reported protein leakage mechanisms and elimination of reactive oxidation species induced by phytochemicals [45], which can be used to explain the result obtained in this study, where protein leakage 


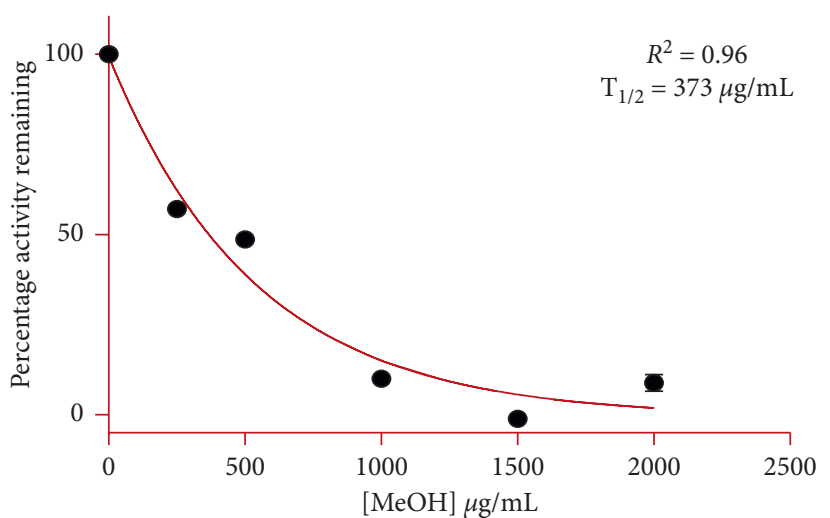

(a)
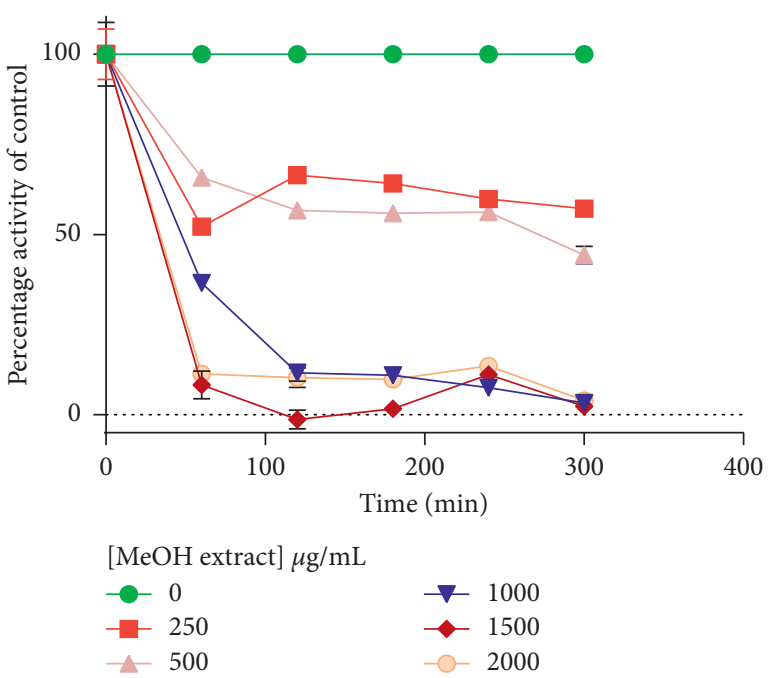

(b)

FIgURE 4: The effects of increasing the concentration of the methanolic (MeOH) extract from P. americana on the activity of $\alpha$-glucosidase enzyme over time (a) and the concentration-dependent effects of the methanol extracts (b).

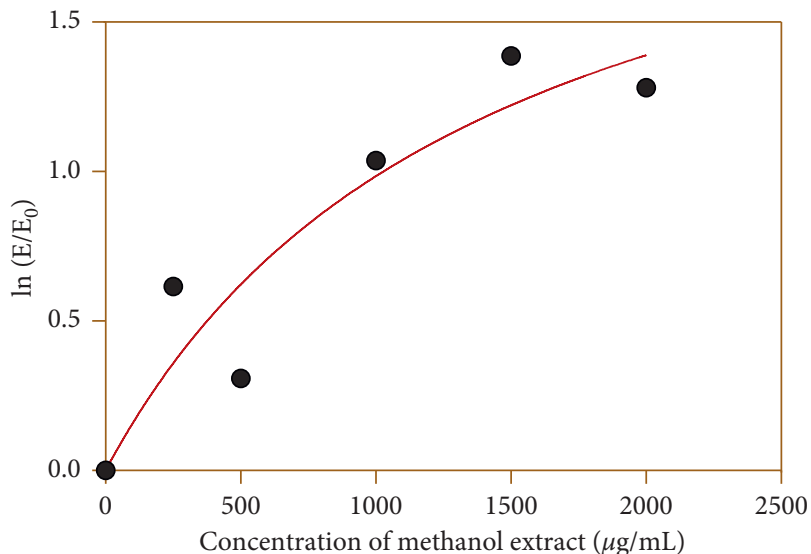

FIGURE 5: A plot of the natural logarithm of the percentage remaining activity of $\alpha$-glucosidase against the pre-incubation times at different concentrations of the methanol extract concentration from $P$. americana.

effects by the ethanol:water and DCM:methanol extracts against $S$. epidermidis were noted but nucleic acid leakage was absent. Results could be explained by the assumption that there was disruption of cell membrane which led to the leakage of proteins [46], but the extracts were not able to act on nuclear membrane, which surrounds nucleic acid material; hence, no nucleic acid leakage occurred [47].

The effects of leaf extracts from $P$. americana on the activity of $\alpha$-glucosidase were investigated. Diabetes is a common metabolic disease characterised by abnormally high plasma glucose levels, leading to major complications, such as diabetic neuropathy, retinopathy, and cardiovascular diseases [48]. One therapeutic approach to treat diabetes is to retard the absorption of glucose via the inhibition of enzymes, such as $\alpha$-glucosidase, in the digestive organs [49]. It has been shown that diabetes can be managed by drinking tea made from leaves of P. americana [19]. Hence, this study determined the effect of leaf extracts from $P$. americana on the activity of the enzyme $\alpha$-glucosidase [17]. The methanol extract was found to have the most potent effect on the inhibition of the activity of $\alpha$-glucosidase (Figure 3(b)). Increase in percentage inhibition as a function of time is indicative of irreversible inhibition [50]. Irreversible inhibition involves the formation of a covalent linkage between the enzyme and the enzyme molecule. This interaction results in inactivation of the enzyme [51]. Accordingly, the methanolic extract exhibited irreversible inhibition on alpha-glucosidase. $\mathbf{K}_{\text {inact }}$ value of $1.4 \mathrm{mg} / \mathrm{mL}$ observed in this study with respect to the methanolic extract may indicate weak binding of the inhibitor to the enzyme molecule. The magnitude of the value indicates the binding affinity of the inhibitor to the enzyme. The smaller the value of $\mathbf{K}_{\text {inact }}$, the better the affinity and the better the binding [52]. The activity of the enzyme with respect to various extract concentrations was observed to decrease with the increase in the concentration of the plant extract, indicating that more enzyme molecules were inactivated at high extract concentrations. The value of $\mathbf{K}_{i}$ may help to determine the time required for administration of a dose to achieve effective inhibition in vivo.

\section{Conclusions}

$P$. americana leaf extracts were shown to have antibacterial activity against $K$. pneumonia and S. epidermidis and extracts have fungistatic activity against C. albicans and C. tropicalis. Disruption of membrane integrity as shown by protein leakage and nucleic acid leakage may be some of the mechanisms of action of the potent extracts. Extracts from $P$. americana leaves also inhibited the activity of $\alpha$-glucosidase. P. americana may serve as sources of lead compounds that may be exploited as potential therapeutic agents to treat 
bacterial and fungal infections in humans as well as partially manage diabetes. Isolation of the bioactive components of the extracts has been suggested for future studies as this may concentrate the active constituent and enhance the effectiveness of the extracts.

\section{Data Availability}

The datasets generated and analysed during the current study are available from the corresponding author upon reasonable request.

\section{Conflicts of Interest}

The authors declare that they have no conflicts of interest.

\section{Acknowledgments}

The authors acknowledge the assistance of Mr. Simbarashe Sithole for the technical assistance. Support from the Swedish International Development Agency (SIDA) through the International Science Programmes (ISP) (ISP IPICS: ZIM01, Uppsala University, Uppsala, Sweden) is acknowledged. ISP IPICS:ZIM01 supported the research under the title "Biomolecular Interactions Analyses." Support from the Alliance for Global Health and Science (University of California, Berkeley) is also acknowledged.

\section{References}

[1] Y. Liu, F. Chan, H. Sun et al., "Resveratrol protects human keratinocytes $\mathrm{HaCaT}$ cells from UVA-induced oxidative stress damage by downregulating Keap1 expression," European Journal of Pharmacology, vol. 650, no. 1, pp. 130-137, 2011.

[2] A. Upadhyay, I. Upadhyaya, A. Kollanoor-Johny, and K. Venkitanarayanan, "Combating pathogenic microorganisms using plant-derived antimicrobials: a minireview of the mechanistic basis," BioMed Research International, vol. 2014, Article ID 761741, 18 pages, 2014.

[3] A. G. Atanasov, B. Waltenberger, E.-M. Pferschy-Wenzig et al., "Discovery and resupply of pharmacologically active plant-derived natural products: a review," Biotechnology Advances, vol. 33, no. 8, pp. 1582-1614, 2015.

[4] J. B. Harborne, Phytochemical Methods: A Guide to Modern Techniques of Plant Analysis, Springer Science \& Business Media, New York, NY, USA, 2nd edition, 2012.

[5] M. Yasir, S. Das, and M. Kharya, "The phytochemical and pharmacological profile of Persea americana mill," Pharmacognosy Reviews, vol. 4, no. 7, pp. 77-84, 2010.

[6] A. B. S. Siqueira, L. R. N. D. A. Rodriguez, R. K. B. Santos et al., "Antifungal activity of propolis against Candidaspecies isolated from cases of chronic periodontitis," Brazilian Oral Research, vol. 29, no. 1, pp. 1-6, 2015.

[7] T. P. Cushni and A. Lamb, "Recent advances in understanding antibacterial properties of flavonoids," International Journal of Antimicrobial Agents, vol. 38, no. 2, pp. 99-107, 2011.

[8] O. Ajayi, S. Awala, O. Olalekan, and O. Alabi, "Evaluation of antimicrobial potency and phytochemical screening of Persea americana leaf extracts against selected bacterial and fungal isolates of clinical importance," Microbiology Research Journal International, vol. 20, no. 1, pp. 1-11, 2017.
[9] A. S. Chhipa and S. S. Sisodia, "Indian medicinal plants with antidiabetic potential," Journal of Drug Delivery and Therapeutics, vol. 9, no. 1, pp. 257-265, 2019.

[10] D. A. Soloviev, S. Jawhara, and W. A. Fonzi, "Regulation of innate immune response toCandida albicansInfections by $\alpha \mathrm{M} \beta 2$-Pralp interaction," Infection and Immunity, vol. 79, no. 4, pp. 1546-1558, 2011.

[11] R. J. Kothavade, M. M. Kura, A. G. Valand, and M. H. Panthaki, "Candida tropicalis: its prevalence, pathogenicity and increasing resistance to fluconazole," Journal of Medical Microbiology, vol. 59, no. 8, pp. 873-880, 2010.

[12] V. Steenkamp, A. C. Fernandes, and C. E. J. V. Rensburg, "Screening of Venda medicinal plants for antifungal activity against Candida albicans," South African Journal of Botany, vol. 73, no. 2, pp. 256-258, 2007.

[13] D. Chessa, G. Ganau, and V. Mazzarello, "An overview of Staphylococcus epidermidis and Staphylococcus aureus with a focus on developing countries," The Journal of Infection in Developing Countries, vol. 9, no. 6, pp. 547-550, 2015.

[14] P. D. Fey, Staphylococcus epidermidis: Methods and Protocols, Vol. 1106, Humana Press, Ohio, NJ, USA, 5th edition, 2016.

[15] T. H. Nguyen, M. D. Park, and M. Otto, "Host response to Staphylococcus epidermidis colonization and infections," Frontiers in Cellular and Infection Microbiology, vol. 7, p. 90, 2017.

[16] C. Chen, M. Kielhlbauch, M. Waters, and A. Kallen, "Panresistant New Delhi metallo-beta-lactamase-producing Klebsiella pneumoniae-Washoe County, Nevada, 2016," Morbidity and Mortality Weekly Report, vol. 1, p. 33, 2016.

[17] S. S. Nair, V. Kavrekar, and A. Mishra, "In vitro studies on alpha amylase and alpha glucosidase inhibitory activities of selected plant extracts," European Journal of Experimental Biology, vol. 3, no. 1, pp. 128-132, 2013.

[18] U. Arukwe, B. A. Amadi, M. K. C. Duru et al., "Chemical composition of Persea americana leaf, fruit and seed," International Journal of Recent Research and Applied Studies, vol. 11, no. 2, pp. 346-349, 2012.

[19] B. Antia, J. Okokon, and P. Okon, "Hypoglycemic activity of aqueous leaf extract of Persea americana mill," Indian Journal of Pharmacology, vol. 37, no. 5, pp. 325-326, 2005.

[20] EUCAST (European Committee for Antimicrobial Susceptibility Testing), "Determination of minimum inhibitory concentrations (MICs) of antibacterial agents by broth dilution," Clinical Microbiology Infectious Diseases, vol. 9, pp. 1-7, 2003.

[21] T. Arun and M. Rabeeth, "Genotoxic effect of paracetamol containing tablets in cultured human lymphocytes," International Journal of Biomedical Research, vol. 1, no. 2, pp. 21-30, 2010.

[22] M. A. El-Nakeeb, H. M. Abou-Shleib, A. M. Khalil, H. G. Omar, and O. M. El-Halfawy, "Membrane permeability alteration of some bacterial clinical isolates by selected antihistaminics," Brazilian Journal of Microbiology, vol. 42, no. 3, pp. 992-1000, 2011.

[23] W. Du, C. Sun, Z. Liang, Y. Han, and J. Yu, "Antibacterial activity of hypocrellin A against Staphylococcus aureus," World Journal of Microbiology and Biotechnology, vol. 28, no. 11, pp. 3151-3157, 2012.

[24] M. M. Bradford, "A rapid and sensitive method for the quantitation of microgram quantities of protein utilizing the principle of protein-dye binding," Analytical Biochemistry, vol. 72, no. 1-2, pp. 248-254, 1976. 
[25] O. H. Lowry, N. J. Rosebrough, A. L. Farr, and R. J. Randall, "Protein measurement with the Folin- phenol reagent," Journal of Biological Chemistry, vol. 193, pp. 265-275, 1951.

[26] M. Bräunlich, R. Slimestad, H. Wangensteen, C. Brede, K. Malterud, and H. Barsett, "Extracts, anthocyanins and procyanidins from Aronia melanocarpa as radical scavengers and enzyme inhibitors," Nutrients, vol. 5, no. 3, pp. 663-678, 2013.

[27] Y.-M. Kim, Y.-K. Jeong, M.-H. Wang, W.-Y. Lee, and H.-I. Rhee, "Inhibitory effect of pine extract on $\alpha$-glucosidase activity and postprandial hyperglycemia," Nutrition, vol. 21, no. 6, pp. 756-761, 2005.

[28] G. R. M. Chelladurai and C. Chinnachamy, "Alpha amylase and Alpha glucosidase inhibitory effects of aqueous stem extract of Salacia oblonga and its GC-MS analysis," Brazilian Journal of Pharmaceutical Sciences, vol. 54, no. 1, pp. 1-10, 2018.

[29] N. Kumar, Z. A. Wani, and S. Dhyani, "Ethnobotanical study of the plants used by the local people of Gulmarg and its allied areas, Jammu \& Kashmir, India," International Journal of Current Research in Bioscience and Plant Biology, vol. 2, no. 9, pp. 16-23, 2015.

[30] B. Moyo and S. Mukanganyama, "The anticandidal and toxicity properties of Lampranthus francisci," Journal of Mycology, vol. 2015, Article ID 898202, 15 pages, 2015.

[31] D. M. Oliveira, F. G. Melo, S. O. Balogun et al., "Antibacterial mode of action of the hydroethanolic extract of Leonotis nepetifolia (L.) R. Br. involves bacterial membrane perturbations," Journal of Ethnopharmacology, vol. 172, pp. 356$363,2015$.

[32] R. Irchhaiya, A. Kumar, A. Yadav et al., "Metabolites in plants and its classification," World Journal of Pharmacy and Pharmaceutical Sciences, vol. 4, no. 1, pp. 287-305, 2015.

[33] M. Obeidat, M. Shatnawi, M. Al-lawi et al., "Antimicrobial activity of crude extracts of some plant leaves," Research Journal of Microbiology, vol. 7, no. 1, pp. 59-67, 2012.

[34] A. Borges, H. José, V. Homem, and M. Simões, "Comparison of techniques and solvents on the antimicrobial and antioxidant potential of extracts from Acacia dealbata and Olea europaea," Antibiotics, vol. 9, no. 48, pp. 1-19, 2020.

[35] R. M. Epand, C. Walker, R. F. Epand, and N. A. Magarvey, "Molecular mechanisms of membrane targeting antibiotics," Biochimica et Biophysica Acta (BBA)-Biomembranes, vol. 1858, no. 5, pp. 980-987, 2016.

[36] M. Korukluoglu, Y. Sahan, A. Yigit, E. T. Ozer, and S. Gücer, "Antibacterial activity and chemical constitutions of Olea europaea L. leaf extracts," Journal of Food Processing and Preservation, vol. 34, no. 3, pp. 383-396, 2010.

[37] Z. A. Zakaria, M. L. Zakaria, Z. Amom, and M. N. M. Desa, "Antimicrobial activity of the aqueous extract of selected Malaysian herbs," African Journal of Microbiology Research, vol. 5, no. 30, pp. 5379-5383, 2011.

[38] F. G. Mugweru, D. W. Nyamai, M. W. Arika et al., "Antimicrobial activity of aqueous extracts of Maytemus putterlickoides, Senna spectabilis and Olinia usambarensis on selected diarrhea-causing bacteria," Journal of Bacteriology and Parasitology, vol. 7, no. 2, p. 270, 2016.

[39] S. Salari, T. Bakhshi, F. Sharififar, A. Naseri, and P. G. N. Almani, "Evaluation of antifungal activity of standardized extract of Salvia rhytidea benth. (Lamiaceae) against various Candida isolates," Journal de Mycologie Médicale, vol. 26, no. 4, pp. 323-330, 2016.

[40] R. Khan, B. Islam, M. Akram et al., "Antimicrobial activity of five herbal extracts against multi drug resistant (MDR) strains of bacteria and fungus of clinical origin," Molecules, vol. 14, no. 2, pp. 586-597, 2009.

[41] A. D. Russel, "Similarities and differences in the responses of microorganisms to biocides," Journal of Antimicrobial Chemotherapy, vol. 52, pp. 750-763, 2003.

[42] M. D. Lenardon, C. A. Munro, and N. A. Gow, "Chitin synthesis and fungal pathogenesis," Current Opinion in Microbiology, vol. 13, no. 4, pp. 416-423, 2010.

[43] K. Saritha, A. Rajesh, K. Manjulatha, O. H. Setty, and S. Yenugu, "Mechanism of antibacterial action of the alcoholic extracts of Hemidesmus indicus (L.) R. Br. ex Schult, Leucas aspera (Wild.), Plumbago zeylanica L., and Tridax procumbens (L.) R. Br. ex Schult," Frontiers in Microbiology, vol. 6, pp. 1-9, 2015.

[44] B. Moyo and S. Mukanganyama, "Antibacterial effects of Cissus welwitschii and Triumfetta welwitschii extracts against Escherichia coli and Bacillus cereus," International Journal of Bacteriology, vol. 2015, Article ID 162028, 10 pages, 2015.

[45] Z. Ling, Z. Xu, W. Liang, J. Mei, and H. Wang, "Antibacterial activity and mode of action Mentha arvensis ethanol extracts against multidrug resistant Acinetobacter baumanii," Tropical Journal of Pharmaceutical Research, vol. 11, pp. 2099-2106, 2015.

[46] C. Fimognari, Dietary and Non-dietary Phytochemicals and Cancer, MDPI, New York, NY, USA, 1st edition, 2018.

[47] A. Banerjee and T. Majumder, The DNA Intercalators of Ethidium Bromide and Propidium Iodide also Bind to Histones, CRC Press, New Delhi, India, 2006.

[48] V. Kumar, O. Prakash, S. Kumar, and S. Narwal, “ $\alpha$-glucosidase inhibitors from plants: a natural approach to treat diabetes," Pharmacognosy Reviews, vol. 5, no. 9, pp. 19-29, 2011.

[49] A. Kimura, J.-H. Lee, I.-S. Lee et al., "Two potent competitive inhibitors discriminating $\alpha$-glucosidase family I from family II," Carbohydrate Research, vol. 339, no. 6, pp. 1035-1040, 2004.

[50] G. C. Adam, B. F. Cravatt, and E. J. Sorensen, "Profiling the specific reactivity of the proteome with non-directed activitybased probes," Chemistry \& Biology, vol. 8, no. 1, pp. 81-95, 2001.

[51] T. S. Maurer and H.-L. Fung, "Comparison of methods for analyzing kinetic data from mechanism-based enzyme inactivation: application to nitric oxide synthase," AAPS PharmSci, vol. 2, no. 1, pp. 68-77, 2000.

[52] G. Scapin, "Structural biology and drug discovery," Current Pharmaceutical Design, vol. 12, no. 17, pp. 2087-2097, 2005. 